P253 (continued)

Evaluation: Previously, feedback was obtained through online webforms with limited quantity and quality. When requesting feedback with online surveys through EMLs, response rates increased $250-300 \%$ and provided more in-depth information about increases in knowledge and positive behavior change. Respondents shared information with over 130,000 people across various venues and age groups.

Conclusions and Implications: In this digital age, it is important to reach people where they are. Many are online and accessing email but are not revisiting websites to look for new content. By notifying people of new content through optional subscriptions to EMLs, 15,000+ are receiving information on a regular basis. This established group provides the opportunity to build constituencies and an established group for behavioral change surveys.

Funding: None

\section{P254 Consumer Subjective Social Feelings as a Function of Snack Type}

James Painter, PhD, RD, LDN, jimpainterphd@gmail.com, University of Texas -Houston, School of Public Health, 2000 Gulf Boulevard, \#901; M. Schuster, MS, RDN, Whidbey General Hospital; J. MacKenzie, MS, RDN; C. Stanek, MS Candidate, Eastern Illinois University; C. Bueno, MS, RDN; E. Shuff, MS, RDN, Crossing Healthcare; K. Kennedy-Hagan, PhD, RDN, Eastern Illinois University

Objective: Determine relationship between consumer subjective social feelings as a function of snack type.

Design, Setting, and Participants: Consumer subjective social feelings will vary as a function of snack type.

Outcome Measures and Analysis: A convenience sample $(n=77)$ of students and faculty was recruited. Participants signed an informed consent and completed pre and post surveys, rating their agreement with the statement: I feel more social when I eat (__ $)$, for six major snack brands (Nacho Cheese Doritos corn chips, Lays potato chips, M\&M candies, Oreo cookies, Wonderful Pistachios, or Ritz crackers) using a 4-point Likert-scale ( $1=$ strongly disagree, $4=$ strongly agree). Subjects then reviewed the food labels from these snacks. The university's IRB approved the study.

Results: At post-intervention, there was an overall difference in feeling social across snacks, $\mathrm{F}(5,370)=3.03$, $\mathrm{p}=0.01, \mathrm{n} 2=0.04$. Post-intervention corn chips, potato chips, candy, cookies, pistachios and crackers were rated: $(1.87,1.95,2.01,1.91,2.26,1.96$ respectively). Pre to post-interventions participants were significantly more social eating pistachios, $\mathrm{t}(74)=1.79, \mathrm{p}=0.04$, but significantly less social eating the crackers, $\mathrm{t}(74)=-1.69, \mathrm{p}=0.05$. Conclusions and Implications: The significant changes in feeling social seen with nuts and crackers may be partially understood by the length of the ingredient list ( 2 and 8 respectively) and number of vitamins \& minerals shown on the label (7 and 0, respectively). Subjects changed their social feeling as a function of snack type after viewing the ingredient list and nutrition facts panel.

Funding: Paramount Farms

\section{P255 Social Media and Dietary Patterns Among College Students}

Kristin Riggsbee, BS, LPN, kolmstea@vols.utk.edu, University of Tennessee, 1215 West Cumberland Avenue, Jesse Harris Building Room 229, Knoxville, TN 37996;

S. Colby, PhD, RD; M. Sowers, MS, RDN; A. Mathews, PhD, $R D N$, University of Florida; M. Olfert, DrPH, MS, RDN, LDN, West Virginia University; M. Barr;

K. Kattelmann, PhD, RDN, LN, FAND, South Dakota State University; T. Kidd, $P h D, R D, L P N$, Kansas State University; T. Horacek, $P h D, R D$, Syracuse University; O. Brown, PhD, RD, Auburn University; A. White, PhD, RD, University of Maine

Objective: To examine relationships between healthrelated social media usage and dietary behavior among college students.

Design, Setting, and Participants: First-year college students ( $\mathrm{n}=1,134)$ were recruited from eight US Universities as part of a larger research project, Get Fruved.

Outcome Measures and Analysis: Bivariate regression analysis was conducted to assess relationships between social media (type used, frequency, and seeking health-related information) and fruit and vegetable (FV) consumption.

Results: Most participants (55\%) reported spending an average of 40 minutes or less on social media daily; however, $45 \%$ reported spending 41 to 120 minutes daily. Facebook and Pinterest were most commonly reported as being sources of health-related information (18\% and $16 \%$, respectively). Most participants (69\%) reported seeking health-related information from social media sources two or less times per month. Participants reported that food purchases were slightly or not at all influenced by social media, and that social media had minimal to no impact on their view of nutrition $(82 \%$ and $70 \%$, respectively). Individuals who sought health-related information on social media sites were likely to consume more FV than those who less frequently sought health-related information on social media $(\mathrm{r}=0.11, \mathrm{p}<0.001)$.

Conclusions and Implications: It is unknown if social media influences health-related behavior or if those interested in health are more likely to seek health-related information on social media. Further research is needed to understand this identified relationship between healthrelated social media usage and behavior.

Funding: USDA

\section{P256 Cultural Differences Expressed by WIC Participants While Evaluating a WIC App for Nutrition Education}

Lesli Biediger-Friedman, MPH, RD, PhD, 1b47@txstate.edu, Texas State University, School of FCS, 601 University Drive, San Marcos, TX 78666; M. Silva, BS;

S. H. Crixell, PHD, RD; K. S. Smith, PhD 